Corps et culture

Numéro 3 | 1998

Sport et lien social

\title{
Michel Maffesoli, analyste de la socialité émergente
}

\section{Yves Le Pogam}

\section{OpenEdition}

\section{Journals}

Édition électronique

URL : http://journals.openedition.org/corpsetculture/522

ISSN : $1777-5337$

Éditeur

Association Corps et Culture

Édition imprimée

Date de publication : 1 juin 1998

ISSN : 1268-5631

\section{Référence électronique}

Yves Le Pogam, « Michel Maffesoli, analyste de la socialité émergente », Corps et culture [En ligne],

Numéro 3 | 1998, mis en ligne le 04 mai 2007, consulté le 07 septembre 2020. URL : http://

journals.openedition.org/corpsetculture/522

Ce document a été généré automatiquement le 7 septembre 2020.

(c) tous droits réservés 


\title{
Michel Maffesoli, analyste de la socialité émergente
}

\author{
Yves Le Pogam
}

1 Il n'est pas aisé d'avoir comme objectif de rendre compte d'une œuvre inscrite dans plus de vingt ans d'écriture, composée d'une douzaine d'ouvrages et d'articles multiples publiés à ce jour et qui traverse le champ de la connaissance sociologique depuis les années quatre-vingt. L'autorité de Michel Maffesoli est attestée par la place qu'il occupe dans la sociologie contemporaine. Ainsi Pierre Ansart rattache ses recherches au courant de la vie quotidienne centré sur l'analyse des rituels quotidiens, des échanges familiers, des fêtes, un courant dont l'extension tient au reflux des grandes idéologies, à l'élargissement des préoccupations ethnologiques et anthropologiques, aux exemples venus des historiens attentifs eux-mêmes à la vie quotidienne des hommes du passé. La place qu'y occupe Michel Maffesoli relève d'une approche phénoménologique construite sur une herméneutique du vécu, ouverte aux sensibilités sociales et aux attitudes pour mieux comprendre la vitalité des groupes, différente en cela de la direction critique de la vie quotidienne développée par Henri Lefebvre (Ansart P., 1990 : $138,319)$.

2 L'idée de vouloir restituer une telle démarche ne peut avoir que les limites de son audace. Limites qui tiennent aux choix méthodologiques imposés par les contraintes de cette note qui se veut respectueuse des idées essentielles travaillées par Michel Maffesoli mais qui laissent inévitablement dans l'ombre des pans entiers de connaissance, ceux qui concernent par exemple les développements et les nombreuses références qui viennent parfaire et amplifier sa pensée. Car Michel Maffesoli pour travailler dans «l'épaisseur du présent » fait preuve d'une réelle culture qu'il puise dans plusieurs sources comme le reconnaît Gilbert Durand, dimensions qu'il est impossible de restituer ici dans le détail (Durand G., 1979: 8). Outre les nécessaires occultations qui ôtent toute une richesse de la pensée, cette réduction peut comporter des distorsions et l'auteur peut ne pas partager les choix opérés, les points de vue exposés et sentir ainsi son travail lui échapper. Ce sont là les risques réels de cette entreprise qui ne remplacera jamais la lecture patiente des ouvrages avec les méandres 
qu'ils comportent, les intuitions qu'ils suggèrent et les liens tissés entre eux qu'ils autorisent.

3 Comment alors rendre compte de quelques traits majeurs de l'œuvre de cet auteur qualifié de "prolifique, esthète dionysiaque et sociologue sensuel du temps présent ", dont la pensée "tourbillonne, effervescente et sensuelle comme les phénomènes sociaux qu'elle entend décrire: elle virevolte autour de ceux-ci pour mieux les effleurer, les sentir, les approcher » (Bolle de Ball M., 1989 : 193-194) ? Un auteur qui en outre est très stimulant pour ceux qui comme lui, se situent en dehors de l'utile, de l'esprit de système, de la demande sociale, des caractéristiques de plus en plus rares dans le monde universitaire. Si la pensée maffesolienne est certes éclatée, la notion de socialité liée au présent traverse son travail, notion qui l'engage sur l'analyse de la profondeur du lien social avec une dimension subversive lorsqu'il montre comment ce lien se fait contre toutes les formes de pouvoir, politique, économique, institutionnel. C'est cette hypothèse de travail qui sert ici de fil directeur à l'analyse qui volontairement reste près de l'écriture de l'auteur, en empruntant très souvent son langage. Pour exposer les idées extraites d'un corpus formé de la lecture de ses ouvrages articulées sur la notion de socialité, le parti pris qui a prévalu ici repose sur une double nécessité : celle de montrer comment la notion a été travaillée dans le temps par Michel Maffesoli, ce qui exige que l'ensemble de ses ouvrages soit analysé, et celle de circonscrire un certain nombre de thèmes récurrents, ce qui implique que les ouvrages soit également lus dans une transversalité. Verticalité et transversalité se conjuguent ici pour tenter de circonscrire la puissance de la socialité souterraine décrite par Michel Maffesoli.

Verticalité : la puissance de la socialité en acte

Il s'agir ici de voir comment la notion de la socialité progresse dans le temps, ceci depuis les premières publications de l'auteur, afin d'en dégager la pertinence. Un moyen méthodologique consiste à tenter de périodiser son travail en cherchant des indicateurs qui témoignent des déplacements d'intérêts, voire des réorientations de méthodes ou des changements d'objets. Or, ce qui frappe a priori dans la sociologie de Michel Maffesoli, c'est la constance de ses hypothèses et les liens très étroits qui existent entre ses ouvrages, ce qui rend difficile une périodisation construite à partir de séparations nettes. Par exemple, la dialectique du pouvoir et de la puissance s'affirme dans sa première publication, Logique de la domination (1976) et aussi dans son dernier ouvrage, Du nomadisme (1997) où il montre comment la modernité induit un pouvoir de domination taraudé par un ensemble de pratiques sociales, comme l'errance, l'aventure, pratiques faites d'une précarité échappant à une logique déterminante et qui confèrent alors au social une puissance contre l'orthodoxie de l'ordre établi. C'est bien à un immoralisme vis-à-vis de l'officiel, de l'unidimensionnalité et de l'ordre, que scrute Michel Maffesoli dans les pratiques banales de la vie quotidienne. Sa sociologie repère des pratiques sociales, des cultures naissantes, qui sont autant de preuves rassemblées patiemment dans la postmodernité pour venir étayer son projet de saisir la dimension plurielle du social, son polythéisme, la socialité en acte. Une socialité pensée comme l'affirmation d'une solidarité de base, son expression quotidienne dans une organicité, différente du social mécanique où les individus sont entre eux d'une manière rationnelle. Cependant, même si l'auteur reste fidèle à quelques principes directeurs qui guident ses analyses dont certains seront évoqués plus loin, il n'en 
demeure pas moins que les objets sur lesquels portent son travail se sont modifiés au cours du temps, tout en restant reliés par une problématique d'ensemble.

Situé dans le temps, son travail sur la socialité peut alors être séparé en trois périodes. Dans un premier temps, Michel Maffesoli installe sa vision dynamique du social dans le cadre d'une anthropologie politique en fixant ses principes dans Logique de la domination (1976), La Violence fondatrice (1978) repris dans Essai sur la violence banale et fondatrice (1984) et La Violence totalitaire (1979). La seconde période paraît plus marquée par l'affirmation de la socialité comme thématique dominante, située dans des ouvrages comme La Conquête du présent (1979), L'Ombre de Dionysos (1982) et Le Temps des tribus (1988). Quant à la dernière période, elle marque une orientation nouvelle initiée par l'esthétique comprise comme lien émotionnel et s'exprime dans des ouvrages comme Au creux des apparences (1990), La Transfiguration du politique (1992) et Du nomadisme (1997).

Une anthropologie politique

6 Les principes d'une anthropologie politique se fixent dans Logique de la domination, un ouvrage bien situé dans la critique de l'époque dans lequel Michel Maffesoli affirme déjà les prémisses de développements ultérieurs, «Ratio, science, technique, schèmes de développement occidental, de par l'autodestruction qu'ils opèrent, en appellent de facto à leur dépassement qui peut d'ailleurs prendre des allures régressives. C'est ce qui se dessine dans les multiples moments subversifs qui ponctuent l'histoire sociale et qui vont en s'accélérant et se diversifiant... ( 1976 : 15). Michel Maffesoli entend montrer la désagrégation de cette logique, dans la socialité, dans sa mouvance, dans une créativité que l'idéologie économique ne peut retenir. Un ouvrage où les concepts majeurs comme, idéologies, utopies, imaginaire sont déjà présents. Cette élaboration théorique liée au politique va se concrétiser dans la thématique de la violence, élaborée et approfondie dans La Violence banale et fondatrice (1984) qui reprend le texte de Michel Maffesoli extrait de l'ouvrage La Violence fondatrice (1978) réalisé en collaboration avec A. Pessin, auquel il ajoute des considérations sur la dynamique dionysiaque puisqu'il a publié entre temps La Conquête du présent (1979) et L'Ombre de Dionysos (1982).

7 Dans son essai consacré à la violence fondatrice, un ouvrage dont la relecture serait nécessaire pour comprendre le contexte actuel, Michel Maffesoli entend la violence comme « une manière commode de rassembler tout de qui a trait à la lutte, au combat, en bref à la part d'ombre qui taraude actuellement le corps social» (1984:14). Cette approche ne renvoie pas la violence à une forme négative, mais la considère dans l'ambivalence de sa pluralité, simultanément destructrice et constructrice du lien social. La violence n'est donc pas une survivance barbare mais une force de structuration du social. En faire un territoire délimité qu'il est nécessaire de réguler, de canaliser par des experts, par une technostructure (appareil judiciaire, police, travail social) normalisant ainsi les différences traitées, conduit le social à la monotonie de l'équivalence généralisée. Michel Maffesoli note cependant que les rituels d'entente de la violence existent, notamment dans les compétitions sportives.

8 Se trouve aussi exprimée ici une grande opposition qu'affectionne Michel Maffesoli, celle des rapports entre l'institué et l'instituant, la dialectique du pouvoir et de la puissance sociale. Car la violence est souvent ignorée par les pouvoirs institués, les appareils bureaucratiques, États, services publics, et il existe une violence anomique qui est simultanément destruction par rapport à l'institué et fondatrice car elle a sa 
dynamique propre. Michel Maffesoli part de l'hypothèse selon laquelle, quand existe une imposition absolue, quand l'ensemble de la vie sociale est quadrillé par la norme, alors l'illégalisme jaillit comme expression d'un "vouloir-vivre irrépressible », d'une souveraineté, signe de la puissance du social comme l'exprime la violence urbaine (1984 : 22). En ce sens, l'anomie révèle un aspect utilitaire, elle permet de comprendre la perdurance sociale et d'assurer le fonctionnement de l'ensemble social: elle est facteur d'équilibre structural (ibid. : 137). Mais la violence elle ne peut se réduire à vue utilitariste, parce qu'elle est sans finalité, inquiétante et revêt une forme symbolique comme passion vécue collectivement (dans une grève par exemple). Elle a une fonction rassemblante, génère du lien en brisant la sérialisation sociale, en se fondant sur l'image d'une société à créer. Elle aboutit à l'échange symbolique et en ce sens, elle est l'expression d'un désir de communion.

Le désordre crée alors de l'ordre en devenant une force structurante, par la dialectique de l'imaginaire et de l'institué. Cette dialogique de l'ordre et du désordre s'objective dans le plaisir de détruire qui se conjugue avec le désir de construire. La violence affirme un vouloir-vivre social résistant à la soumission. Elle est résistance et affirmation d'énergie.

Michel Maffesoli affirme là son goût pour ce dynamisme social qui ouvre à l'excès, au sentiment anarchiste qui sourd des individus et que traduit cette énergie de vie qu'il repère dans la parole qui rompt la sécurité de l'institué, le rire qui exprime la subversion, l'orgiasme et la fête qui jouent de manière paroxystique le rapport à la dépense, à la déperdition, à la dissolution (ibid. : 83). Ce sont là autant de directions qui autorisent l'expression de la solidarité, dans les résistances ou dans les souffrances. La socialité ne signifie pas que le conflit soit absent, elle est faite d'une pluralité d'attitudes et d'idées mêlant le sujet à un collectif, collectif toujours en acte car soumis à l'aléa. En étant assumée par la parole, l'orgie ou la fête, la violence participe d'une manière fonctionnelle à la restauration de l'harmonie. La violence anomique a une fonction fondatrice.

11 Mais il existe aussi une autre violence, banale et qui se lit dans les résistances de la masse, dans les passions sociales, dans le dynamisme dionysiaque. Ici, Michel Maffesoli s'attache à rechercher les passions minuscules constitutives de la socialité et qui se réalisent loin du politique et de l'économique. Une anthropologie qui montre comment le présent compte plus que le devoir-être du temps de la gestion ou de l'économie et qu'il repère dans la jouissance. Dans le quotidien s'affirme la prégnance du sensuel, une résistance passive à l'égard du politique et des discours sur la libération, sans renoncer à un avenir meilleur. Une résistance qui s'affiche dans la ruse et la duplicité, signes de la souveraineté sociale et qui affaiblissent le pouvoir en subvertissant ou en relativisant les valeurs dominantes, en refusant de répondre aux demandes, en développant les formes de l'illégalisme. Des directions qui permettent d'échapper au contrôle généralisé et à la perte d'identité. La socialité s'organise entre deux pôles : celui de l'acceptation et celui de la différence.

12 Cette réflexion sur la violence développée dans la pensée maffesoliennne, liée à la socialité et ancrée à un au-delà du politique, se poursuit dans La Violence totalitaire. Ici la notion de totalitarisme traverse l'ouvrage, une emprise diffuse ou autoritaire d'institutions étatiques sur les activités de la vie sociale. Les oppositions se manifestent entre le pouvoir fait pour gouverner, domaine du politique, et la puissance qui est la violence sociale née de l'agrégation et du collectif qui lutte contre la gestion rationnelle 
et bureaucratique. Michel Maffesoli montre l'échec actuel des formes de révolution et à la notion d'ordre, faite de conservatisme qui lui est consubstantielle, s'oppose la routine du quotidien, même si la révolution, comme la fête, dans ses caractères d'excès et de transgression, a une fonction de fondation en instaurant une communauté, un être-ensemble situé au-delà des associations rationnelles. Les processus révolutionnaires structurellement engendrent un conservatisme.

Les linéaments d'une anthropologie politique développés ici, l'idéologie du progrès dans sa capacité à générer du bonheur, le bonheur produit par le travail qui nécessite une organisation et une soumission aux dispositifs de l'autorité, ne se retrouveront plus sous cette forme dans son travail ultérieur d'observation de la vie quotidienne. Deux traits majeurs dominent alors dans la société capitaliste : la nécessité de travailler et l'idée selon laquelle la société se développe sous le regard protecteur de l'État avec ce que cela implique de rationalisation instrumentale, de directions normatives, de bureaucratisation et de développement du quantitatif. L'idéologie du progrès produit un effet pervers: sous prétexte de servir l'homme, le progrès lui ôte sa substance. Michel Maffesoli, contrairement à une théorie critique qui proposerait des alternatives, n'émet pas de propositions sur une politique idéale à réaliser ou sur une société parfaite, mais il met en question des formes constitutives de la modernité comme la révolution, le progrès, en montrant leur échec et en laissant la place à un autre temps : le présent. C'est là une deuxième dimension qui ouvre à l'affirmation de la socialité.

La force de ses premières publications se comprend mieux. Moins connues que celles qui suivent, elles contiennent les soubassements sur lesquels vient se greffer l'anthropologie de la vie quotidienne dont il va progressivement parfaire les formes.

L'affirmation de la socialité : un "nouvel esprit anthropologique »

Bien que le terme de "nouveau sociologue » pour qualifier des publications originales soit toujours l'objet de méfiance dans le champ de la connaissance, Gilbert Durand défend cette acception à propos de Michel Maffesoli dans sa préface à La Conquête du présent (1979). Cette qualité lui paraît justifiée dans la mesure où cet ouvrage s'inscrit dans ce qu'il avait analysé lui-même sous le vocable " Nouvel Esprit Anthropologique » (Durand G., 1975, 1985), c'est-à-dire la prise en compte du polythéisme des valeurs, de l'hétérogénéité du social, à quoi il faudrait ajouter, la prise en compte de la qualité de la vie qui prend le pas sur les procédures de gestion et de production finalisée, la présence d'un nouveau dieu, Dionysos contre le progressisme titanesque, l'intérêt pour tout ce qui échappe à l'utilitarisme (La part maudite de G. Bataille). Tout cela marque un renversement épistémologique où la culture est privilégiée par rapport à l'économie et où l'importance du mythique, du symbolique et de l'imaginaire est valorisée et non plus le dualisme marxiste infrastructure-superstructure. C'est aussi une "nouvelle» sociologie de la «profondeur de l'épaisseur et de l'opacité, de la profondeur des liens sociaux » (Durand G., 1979: 11).

Dans La Conquête du présent le projet de Michel Maffesoli est de se consacrer à la trame du présent où s'affirme la socialité et dont Gilbert Durand reconnaît le caractère subversif car il dénonce « les fanatismes de la transparence et des iconoclastes, fussentils révolutionnaires » (Durand G., 1979 : 11). Ici encore, Michel Maffesoli n'entend pas imposer ou dire ce que doit être une politique de la vie quotidienne, mais seulement montrer les formes de son expression, notamment la socialité multiforme souterraine, que ne peut expliquer l'analyse économique ou politique. La socialité de base qui conduit à une harmonie différentielle rompt avec le totalitarisme qui repose sur une 
harmonie unifiée. Il s'agit bien ce capter l'immoralisme envers l'officiel ou l'idéologie dominante (Progrès, Raison), c'est-à-dire marquer l'antagonisme entre la puissance et le pouvoir. Où saisir les formes de ce dynamisme social si ce n'est dans les échanges (don et contre don) qui apparaissent comme une structure sociale, dans une socialité en jeu saisie dans le ludisme (jeu, débauche), dans le sport (émotions partagées), dans le sensualisme (fête) ? Une socialité qui s'inscrit aussi dans une espace, un territoire qui l'irrigue de sens. Il existe un sensualisme local où s'exprime la socialité de base grâce à la force de l'imaginal (la ville comme espace de socialité par exemple).

La fantastique quotidienne s'ancre à l'imaginaire qui structure cette socialité en renversant la prétendue efficacité du discours dominant. Dans ce sens, Michel Maffesoli développe les multiples facettes de ces reprises d'initiatives qui confèrent du sens à l'existence. La ruse, la duplicité, le rite, témoignent tous d'une soif du présent et d'une résistance à la planification de la vie. La ruse constitue ainsi un véritable bouclier contre l'imposition de l'ordre social, contre la domination, la contrainte, la répression, en permettant de conserver un «quant-à-soi ». Cette proximité avec le présent s'illustre aussi dans la puissance de rites dont $\mathrm{E}$. Goffman a révélé toute la force de ce qu'il appelle une "sociologie des circonstances", faite de la banalité de tous les jours (Goffman E., 1974). Et Michel Maffesoli s'érige contre les critiques du spectacle car les rites sociaux ne lui paraissent pas aliénés, ils fonctionnent sur la duplicité, sur une lucidité sans illusion, jointe à un investissement réel. Ce double jeu ou duplicité est une protection et traduit le "sentiment tragique de la vie ", à comprendre, non pas comme des états d'âme, mais comme «la conscience du fait que toutes situations, toutes attitudes s'épuisent dans le moment même de leur effectuation » $(1979$ : 127). A propos de la duplicité, Michel Maffesoli introduit le notion de "forme" qui prendra une ampleur méthodologique dans la suite de ses recherches, forme comprise dans le sens où la duplicité n'existe pas à l'état pur, mais elle peut éclairer de nombreuses pratiques. C'est bien au fondement de la dynamique sociale auquel s'attache Michel Maffesoli en montrant que la duplicité structure le social.

Ainsi s'affirment des idées force qui, initiées par l'anthropologie politique, vont irriguer tout son travail ultérieur : l'importance donnée à l'insignifiant, au banal, rappelé par la permanence des rituels qui se rapportent au ludisme, la reconnaissance du qualitatif comme source de valorisation devant la saturation des valeurs comme le productivisme et le progrès qui ont fait le succès de la pensée bourgeoise, la force de la poésie du quotidien, bref des dimensions minorées dans l'espace de la connaissance et qui reposent sur l'image, l'apparaître, l'insignifiant. C'est là une voie qui va se parfaire dans L'Ombre de Dionysos, où le rôle de la passion, des affects est valorisé.

Le point de départ de L'Ombre de Dionysos repose sur le même postulat: scruter dans le présent des formes rassemblantes qui servent de contrepoint aux valeurs dominantes de la modernité. Une hypothèse qui suggère que la figure d'un Prométhée laborieux s'attarde dans un endroit où il n'a plus sa place et est remplacé par le bruyant Dionysos. C'est l'émergence d'une structure comme l'orgiasme que pointe Michel Maffesoli qui entend bien, contre l'excès du principe d'individuation ou de celui de l'individualisme, montrer que l'homme est une "être-ensemble ». L'orgiasme met en jeu la socialité, définie comme l'expression quotidienne et tangible de la solidarité de base, renvoyant à une solidarité organique, permettant l'épanouissement de chacun dans un ensemble plus vaste, dans le collectif (par exemple la circulation des sexes). Il est l'expression d'une pulsion d'errance toujours vivace malgré la domestication des mœurs ou les 
changements technoscientifiques et économiques. Car ce qui prévaut pour Michel Maffesoli, c'est le renversement de la morale tyrannique du devoir être, dictée par la société, pérennisant l'ordre établi et qu'il oppose à une éthique faite d'effervescence et de désir de réaliser l'impossible: «Ce n'est pas en se libérant des contraintes économico-politiques, ce n'est pas en luttant contre les diverses formes d'aliénation que la communauté existe, mais c'est peut-être en vivant au jour le jour le contradictoriel passionnel et affectif » (1979: 138). Tout comme la duplicité, l'orgiasme est une "forme" permettant de comprendre une multiplicité de situations qui échappent à l'injonction morale dont le jeu passionnel est très étendu (jeu pervers du monde enfantin, lubricité des fêtes populaires, intrigues amoureuses, etc.), et qui en outre, rompent avec le bourgeoisisme utilitariste jamais détaché de l'avenir qui n'accepte pas les pratiques réalisées pour la perte de la vie improductive, des pratiques liées au présent, construites sur une pluralité de valeurs créant pourtant un lien sociétal.

20 Alors c'est la massification du carpe diem qui est décrite, la jouissance fondée sur les sensations, les images, une éthique du moment et que ne peut contenir l'ordre comptable et productif de l'économie dominante. Le rationalisme ne peut reléguer le ludisme et l'effervescence continue. Prométhée doit cohabiter avec Dionysos une figure nécessaire de la socialité. La jouissance productive ne peut exclure la jouissance non finalisée et Michel Maffesoli va s'intéresser au «divin social», à la présence d'une " centralité souterraine ", c'est-à-dire à la perdurance d'une socialité. Le divin social est une formule qu'il affectionne pour comprendre le polythéisme dans toute sa dimension et elle s'illustre concrètement par de nombreux exemples tirés de l'ethnologie, notamment par le rapport au sexe auquel il veut donner toute son efficace contre le soupçon, qu'il s'agisse des fêtes corrobori décrites par E. Durkheim où l'échange des femmes, les passions catalysent la vie quotidienne, ou les analyses sur la bisexualité. Mais le ludique est traversé aussi par la mort (fêtes primitives, carnavals), une mort qui côtoie le sexe. De même l'orgiasme s'inscrit sur un fond de violence, même s'il la ritualise et l'apprivoise, comme en témoignent certains rituels dévoilés par Malinowski en Mélanésie où l'homme est une victime sexuelle des femmes, un rituel qui revient quand les femmes sont soumises à un travail pénible.

21 L'orgiasme apparaît comme un facteur de socialité et Dionysos est une figure qui se retrouve dans plusieurs sociétés et comme telle, peut être considérée comme une "structure anthropologique " (carnavals, Fête des fous) où le burlesque, l'ironie et la dérision, des formes de désordre, régénèrent le corps social. Et Dionysos est aussi le dieu du vin et du sexe dont la charge anthropologique doit être prise au sérieux. La boisson sert de liant et de lien social et Bacchus renvoie à la figure double de la régénération et de la mort. Bref, Michel Maffesoli plaide pour l'invariance de l'orgiasme dans laquelle la perspective dionysienne permet de maintenir ensemble, d'une manière tensionnelle, tous les éléments du social : la stabilité des moeurs paraît intolérable sans l'errance et la raison est rapidement mortifère sans la présence de la démence.

22 L'Ombre de Dionysos est un fervent plaidoyer pour un hédonisme populaire que Michel Maffesoli va amplifier dans Le Temps des tribus, en montrant que les résistances populaires sont des signes de la vitalité et de la générativité du social, visibles dans l'émergence de micro groupes qui se constituent en réseaux, dont la vigueur exprime la créativité des masses. Apparaît ici une nouvelle notion qui va servir de pivot à ses interrogations futures, la postmodernité. 

du partage sentimental de valeurs, de lieux ou d'idéaux, qui à la fois sont tout à faits circonscrits (localisme), et que l'on retrouve, sous des modulations diverses, dans de nombreuses expériences sociales» (1978: 33), Michel Maffesoli veut rendre compte d'un processus de désindividualisation, de saturation de la fonction qui lui est liée en accentuant la notion de rôle que chaque personne (persona) est appelée à jouer en son sein. Il veut montrer que la socialité fondée sur l'empathie remplace le social rationalisé. Il oppose ainsi la modernité définie par une structure mécanique composée d'individus répondant à une fonction et à des formes d'interaction contractuelles, à la postmodernité, une notion qu'il introduit dans ses analyses et qui se caractérise par une structure complexe et organique, avec ses masses, ses personnes et des tribus qui jouent un rôle à l'intérieur des différentes activités de la vie quotidienne. Au social de la modernité, Michel Maffesoli oppose la socialité de la postmodernité liée au pouvoir des affects (sentiments, émotions) et où s'affirme la présence d'une centralité souterraine.

Cest cet au-delà de la modernité faite des valeurs du bourgeoisisme qui intéresse Michel Maffesoli, c'est-à-dire la socialité faite de liens émotionnels, fondée sur une "reliance", vécue pour elle même, construite sur des valeurs comme la désindividualisation, la dépense, le hasard, la valorisation de petits riens, une communication non finalisée et où se constituent les réseaux d'amitié ou d'entraide, un tribalisme fait de sentiments communs révélés par la connaissance sensible. L'aliénation de l'existence sociale n'exclut pas que puissent s'y décrypter des formes de solidarisme et l'attitude critique ne permet pas de valoriser l'affirmation de la vie, le "vouloir vivre sociétal» qui sert de support à la vie quotidienne. Ici, de nouveau, s'affiche la puissance qui met en oeuvre la profondeur des communautés éclatées mais cependant reliées, créant le paradoxe d'une «harmonie différentielle ». L'affirmation du vitalisme populaire "sonne le glas de la modernité " (1978:56) et à côté du mécanique, du rationnel, de l'instrumental, des valeurs comme l'organique, l'imaginaire et l'affectuel, deviennent des possibles pour réenchanter le monde, sans forcément s'opposer au pouvoir. La vie s'organise donc par des rencontres, par des expériences au sein des divers groupes auxquels chaque individu appartient.

tes affects doit être prise en compte pour comprendre la socialité élective et même si le pouvoir économique n'est pas absent d'une certaine forme de dépense commercialisée (dans les fêtes villageoises, festivités, rassemblements folkloriques), le resserrement de liens collectifs se réalise cependant.

En outre Michel Maffesoli veut positionner son questionnement sur le tribalisme par rapport à une tendance des recherches du moment centrées sur l'individualisme et le narcissisme. Ce sont là des vues qui lui paraissent convenues même si l'existence de l'individualisme ne peut être niée pour expliquer la dynamique de la modernité. Mais tout cela est contrebalancé par son contraire, par une nébuleuse affectuelle, par les réseaux de solidarité. De plus, le tribalisme ne doit pas être considéré comme une survivance archaïque puisque, tant au Japon que dans la Silicon Valley, le groupisme ou la tendance communautaire est l'objet d'attention pour parfaire la performativité humaine et techno-économique de l'entreprise. D'autre part, le tribalisme ne peut-il pas être accusé de régression? Ne favorise-t-il pas la personne et non l'individu ? Cela peut paraître juste pour Michel Maffesoli si on considère que l'autonomie individuelle est «l'horizon indépassable de toute sorte » (1988: 44), mais l'observation de pays comme le Brésil ou le Japon, détachés de l'individualisme, montre qu'ils manifestent 
cependant une vitalité indéniable: «En alternative au principe d'autonomie (autogestion, autopoiésis) existe un principe d'allonomie qui repose sur l'ajustement, sur l'accommodation, sur l'articulation organique à l'altérité sociale et naturelle » (ibid. : 44).

Alors, toutes ces observations permettent à Michel Maffesoli de formuler sous le mode du divertissement, ce qu'il appelle des « lois sociologiques », par exemple : «Ce qui est privilégié est moins ce à quoi chacun volontairement adhère (perspective contractuelle et mécanique) que ce qui est émotionnellement commun à tous (perspective sensible et organique)» (ibid.: 32), ou encore, "Les divers modes de structurations sociales ne valent que dans la mesure, et si elles restent en adéquation avec la base populaire qui leur a servi de support " (ibid. : 80), ou enfin, «Le pouvoir peut et doit s'occuper de la gestion de la vie, la puissance quant à elle est responsable de la survie » (ibid. : 84).

Dans cette période marquée toujours par l'empreinte de l'anthropologie politique, Michel Maffesoli s'attache à montrer les formes d'une socialité naissante, turbulente, signe de la dynamique sociale dans laquelle la puissance des affects est dominante. Sans renoncer à ses conceptions sur la socialité, il l'examine en se positionnant par rapport aux notions majeures qui traversent l'espace de la connaissance, l'individualisme, la postmodernité. La puissance de la socialité va retrouver de nouveaux élans avec la théorisation du paradigme esthétique.

Le lien émotionnel et la puissance de l'esthétique

C'est l'interrogation de la socialité par le paradigme esthétique qui caractérise cette dernière période, esthétique comprise au sens où l'accent est mis sur l'émotion. Sa pensée se renouvelle alors pour questionner le quotidien dans trois ouvrages, Au creux des apparences (1990), La Transfiguration du politique (1992) et dans sa dernière publication, Du nomadisme (1997).

30 La parution de Au creux des apparences, tout en maintenant une réflexion sur la socialité et en continuant à emprunter aux idées exposées précédemment, suggère de nouvelles interrogations dont la source est l'esthétique. Ici, Michel Maffesoli n'oppose plus la modernité à la postmodernité, mais s'installe dans cette dernière pour la théoriser et la mettre en relation avec la construction de l'homo estheticus afin de chercher, plus loin encore, des éléments de compréhension pour vivifier ses analyses et mieux appréhender la complexité de la socialité.

31 Dans $A u$ creux des apparences, Michel Maffesoli approfondit et réinterroge la trame constitutive de ses recherches antérieures: la nature émotionnelle du lien social, l'hédonisme du quotidien, l'être-ensemble, le plaisir des sens, la reconnaissance du futile et de l'inutile, une connaissance ouverte à la raison sensible et à l'organicité qui caractérise la postmodernité, tout ce qui a trait à l'esthétique. Il définit l'esthétique (aisthésis) comme le sentir commun, un consensus sur le plaisir partagé, un sens qui ne la réduit pas aux œuvres de la culture, mais qui consiste à « faire de la vie une œuvre d'art ». C'est là un principe qui ne se concerne pas quelques individus, mais qui est devenu une injonction de masse. Cette esthétique de l'existence se construit sur une deuxième idée force, celle d'une éthique qui fonde une communauté, qui agrège, qui crée des liens favorisant l'attraction/répulsion. L'éthique de l'esthétique est le fait "qu'éprouver ensemble quelque chose est facteur de socialisation » $(1990(1993): 32)$ et Michel Maffesoli fait hypothèse que le paradigme esthétique se présente comme un angle d'attaque permettant de rendre compte d'une constellation d'actions, de sentiments, d'ambiances spécifiques de l'esprit du temps de la postmodernité, ce qui 
caractérise une culture en train de naître (ibid. : 45). C'est ce nouvel esprit du temps qu'il décrypte dans le vitalisme social, ou comme il aime à le dire, dans le "grouillement vitaliste", ou encore dans la créativité populaire en focalisant son attention sur la fonction sociale l'émotion esthétique car elle n'est pas qu'un simple phénomène psychologique. L'émotion est ici pensée comme un véritable structure anthropologique qui permet l'attraction des sensibilités pouvant engendrer de nouvelles formes de solidarité. Elle est activité communicationnelle. Le corps dans ses usages en est un exemple. Le corps mis en valeur, "épiphanisé ", selon une formule qu'il affectionne, dans la publicité, la mode, la danse, le jogging ou dans les techniques orientales, est construit pour être vu. Il s'agit là d'une socialisation : celle d'intégrer dans un ensemble et de transcender l'individu (ibid. : 34).

C'est toujours cette logique de l'être-ensemble, les rapports sociaux qui s'esquissent de nos jours qui passionnent Michel Maffesoli dont le paradigme esthétique permet de capter les effets, à condition de valoriser un hédonisme sans soupçon et se saisir l'existence dans son esprit chaotique et pluraliste. D'ailleurs ce processus d'extraversion se manifeste dans nos société «somatophiles» (aimant le corps, l'exaltant, le valorisant), non pas en y voyant un phénomène de narcissisation auquel pourrait laisser croire le body building par exemple, mais dans la cristallisation au niveau de la personne d'une ambiance collective. Cette valorisation du corps peut être lue à travers la distinction que Riegl fait entre le style optique (mécanique, renvoyant au lointain) et tactile (ou haptique, proche) qui accentue le contact, d'ordre organique : le corps renvoie au palpable, au toucher ainsi que le note Michel Maffesoli lors de rassemblements sportifs ou festifs où se réalise une « reliance ».

Il existe là une « culture du sentiment » reposant sur le plaisir, le désir d'être-ensemble, sans but particulier, sans valeur morale, définissant un nouvel esprit du temps produit par la capillarisation dans le corps social de valeurs qualitatives présentes dans la contre culture des années soixante. Cette culture fondée sur le sentiment, l'émotion, l'imaginaire, le ludique montre que la socialité n'est pas un ensemble de relations simplement mécaniques mais qu'elle s'attache au sensible de l'existence et s'objective dans les agrégations sociales où tous les sens sont sollicités plus un sixième qu'ajoute Michel Maffesoli, le génésique dont l'importance se perçoit dans la recherche amoureuse. La compréhension du lien social passe alors par l'intégration de paramètres non rationnels comme le sont le rêve, le ludique, l'imaginaire, le plaisir des sens. Elle passe aussi par une conjonction sensualiste qui fait du sensible une condition de la connaissance et qui joue comme valorisation du sens commun : «Le sensible, en tant que catégorie empirique, et le sens commun en tant que catégorie philosophique, redonnent goût au bonheur terrestre" (ibid.: 64). Le sensualisme dans la vie quotidienne dynamise les rapports sociaux et permet l'émergence de nouvelles manières d'être-ensemble ou de formes de solidarité. Un consensus renait alors qui repose sur le partage du sensible, comme cela s'observe dans les fêtes, l'hédonisme populaire ou le libertinage. Ainsi, l'agressivité, le conflit, l'individualisme, sont autant de facteurs auxquels répondent l'expérience partagée, comme force d'attractive.

Il est un autre facteur de la socialité travaillé ici par Michel Maffesoli, les apparences, compris lui aussi comme une «forme » (c'est-à-dire insistant à la fois sur l'importance de la globalité et de la profondeur de l'apparence) pour rendre compte de la structure organique qui caractérise les cultures naissantes. En ce sens, les pratiques corporelles (body building, soins du corps, cosmétique, théâtralité) sont pour Michel Maffesoli 
situées en un lieu, avec d'autres, situées par rapport aux autres. Ce "situationnisme " permet de comprendre «que les jeux de l'apparence s'inscrivent dans un vaste champ symbolique dont les effets sociaux sont loin d'être négligeables" (ibid. : 136). Et s'il existe un narcissisme, Michel Maffesoli préfère parler d'un narcissisme de groupe né de la conformisation des apparences. L'apparence induit donc un rapport à l'autre, sollicite le collectif. La mise en valeur des corps conjoint deux entités séparées : comme vecteur de socialité elle désindividualise et permet simultanément de rester soi-même.

Une synergie existe d'autre part entre la socialité et l'espace dans lequel s'exprime le fait de sentir, d'éprouver en commun, et où s'établit une "reliance", un terme qui permet à Michel Maffesoli de saisir un changement d'épistèmê qui s'opère dans la contemporanéité. Ceci s'illustre dans le réseaux, dans des lieux emblématiques que Michel Maffesoli appelle les «Hauts lieux », c'est-à-dire des espaces de socialité faits d'affects et d'émotions, où son corps est construit avec les autres, des lieux qui peuvent être les salles de gymnastique, les squares, etc. Les émotions collectives se diffractent dans le quotidien et délimitent une socialité où domine une ambiance esthétique. La socialité contemporaine pour Michel Maffesoli est prise d'une véritable transe qui marque une extase (fusion, dépossession dans une ensemble plus vaste) et une entase (processus où on prend possession de soi-même), où circulent les apparences, les appartenances diverses à des communautés permettant les identifications, les différentes personnalités et la multiplicité des cultures qui la travaillent au corps.

A partir de l'esthétique, Michel Maffesoli renouvelle son approche de la socialité en se centrant sur l'émotion considérée comme une structure anthropologique, mise en rapport avec la culture naissante de la postmodernité dont la "reliance » serait le paradigme. La socialité est irréductible à des relations mécaniques. Elle implique un lien social dynamisé par l'imaginaire, le ludique et le sensible dont il s'agit de montrer la structure organique. Une entreprise que poursuit Michel Maffesoli dans La Transfiguration du politique en revenant sur ses premiers questionnements, mais où le politique est réinterrogé par des notions développées entre temps.

Ici, les émotions communes et leur efficace servent de fil conducteur à des objets que sont les communautés ou les États-nations, en partant de l'idée selon laquelle «le politique a fait son temps", au sens où le présentéisme a supplanté l'utopie des lendemains qui chantent. Le regard se porte alors sur une socialité dont les formes sont réactionnelles ou passives à l'égard du politique qui dit ce qui doit être, formes qui s'observent dans les explosions ou les implosions, dans la recherche de la ruse pour préserver un "quant-à-soi », dans l'indifférence vis-à-vis du politique, dans les revendications ou les tribalisations. Ici encore, toute la force imaginale est sollicitée pour comprendre les implosions face à la rigidité de l'institué, signe de l'affirmation de libertés interstitielles. Ainsi, à partir d'une nouvelle forme, le politique, Michel Maffesoli renoue plus fortement avec sa critique d'un ordre établi, normatif qui tend toujours à l'État de droit décrétant les conduites des individus sans tenir compte de la pluralisation des affects.

Le souhait se fait encore plus fort de renverser l'idée d'une construction rationnelle de la société qui veut asservir au nom de la raison unique et où le pouvoir est animé du fantasme unitaire sans admettre les composantes pluralistes présentes dans la société. L'excès d'ordre génère une passion sauvage et l'implosion sociale n'en est que la conséquence. L'effervescence sociale est générée par un rationalisme exacerbé qui pousse à la concentration. Le désordre qu'il produit permet aussi de désamorcer les 
conflits. Ici s'exprime la force imaginale combattue par le rationalisme. C'est la socialité dans sa fonction alternative qui est ici interrogée depuis le point de vue du politique, comme capacité à structurer, à fédérer des affinités rompant avec un modèle conçu $a$ priori, ou avec des lois gérant le lointain.

Michel Maffesoli montre la toute puissance de l'utopie comme force de déstabilisation du pouvoir et la dynamique incessante qui lie l'institué à l'instituant : «L'implosion du politique n'est plus à imputer à quelques groupes subversifs, ni à un chef d'orchestre hypothétique, mais l'implosion traduit un état de la société » (1992, (1995) : 73). Les experts, les managers centrés sur la planification et les prospectives, se heurtent à la doxa que traduit bien des expressions comme " au coup par coup " témoignant de la force de l'imaginal de l'être-ensemble qui fait éclater la pensée programmée: l'organique, la puissance se substituent au pouvoir mécanique. Il existe aussi des formes subtiles de déstabilisation du politique que sont la ruse et l'ironie qu'illustre la métaphore qu'emprunte assez souvent Michel Maffesoli à Simmel, celle du Pont et de la Porte, pour montrer que l'on est tout à fait d'un lieu (pont qui relie) sans en être totalement (porte qui sépare). Cela s'illustre par une socialité de type ludique repérable dans le travail où se met en place un ensemble de pratiques pour échapper à l'œil panoptique de l'autorité, dans l'économie informelle, dans les fêtes, le temps libre, les loisirs qui sont autant d'espaces de respiration, d'expression du vitalisme, du vouloir vivre, contre la programmation. L'anomie n'est plus négative, elle participe à la régénération du social.

Ainsi la puissance de la socialité de base s'affirme dans une culture du sentiment qui transfigure le politique puisque l'émotion prend le pas sur le rationnel. L'importance des affects, des sentiments, désigne alors les contours de la socialité (re)naissante perceptible dans les communautés, les clans ou les tribus. Ainsi le mouvement de l'hypertrophie de la culture objective de la postmodernité (production, science, finalisation, utilité) laisse place aux «nous » communautaires, à l'organique revivifié actuellement par la place accordée à l'émotion, à la résurgence du sentiment et de la passion telle que les effervescences ludiques (fêtes, festivals, sports) le laissent paraître. Tout cela traduit pour Michel Maffesoli un sentiment d'appartenance qui n'a plus rien à voir avec le politique.

41 Ici se retrouvent donc amplifiées et rapportées à l'espace du politique, toutes les forces, qui sous des formes différentes, permettent de montrer sa saturation, opérant une transmutation produite par la maximisation des affects. La passion existe dans un monde de raison. C'est là une voie que va approfondir Michel Maffesoli dans $D u$ nomadisme.

Dans cet ouvrage, le projet de Michel Maffesoli est bien de poursuivre par la socialité, l'investigation de ce qui existe à côté de la raison. L'errance a un aspect fondateur et c'est un analyseur de la révolte contre l'ordre établi car elle travaille en profondeur contre les valeurs utilitaires du corps social. Errance ou nomadisme expriment une socialité en gestation, un projet d'être, une synthèse culturelle déterminant les formes de l'être-ensemble.

En ce sens, le nomadisme est contraire à la domestication recherchée par les Étatsnations qui se méfient de ce qui ne peut être contrôlé : le mouvant, le turbulent, ce qui échappe au regard panoptique (les hippies d'hier, les poètes, les jeunes sans repères). La présence de cet à côté, signifie que la violence totalitaire s'inverse en montrant des signes de faiblesse. La manifestation de cette circulation qui s'intensifie se réalise de 
manière silencieuse. Michel Maffesoli décrit là une ambiance, un autre style de la contemporanéité, un nouvel esprit du temps dont les formes sont parfois subtiles à l'exemple de la sensibilité bouddhiste qui se constitue contre les valeurs prométhéennes, manifestant un retour à la tradition. L'errance n'est pas une attitude marginale, rêveuse, elle imprègne fortement l'homme postmoderne.

Fidèle à ses conceptions sociologiques, Michel Maffesoli ne psychologise pas ces pulsions d'errance en cherchant des raisons personnelles à la pensée aventurière, mais les considère comme des vecteurs de socialisation, comme des pôles essentiels à la structuration du social. Exister, c'est pour Michel Maffesoli, sortir de soi, s'ouvrir aux autres, même de manière transgressive, et l'errance lui apparaît comme une constante anthropologique qui taraude chaque individu et le corps social dans son ensemble (1997 : 31). La fonction imaginale du nomadisme, comme forme instituante, relativise par là même la pesanteur de l'institué, signe que l'économique ou le conformisme intellectuel ne peuvent occulter ce désir d'errance qui paradoxalement est constructeur. Le nomadisme en effet contribue à la construction de la réalité sociale contemporaine intégrant une grande partie de symbolique, comme le montre l'accentuation de l'écologique par rapport à l'économique ou les implications de formes communautaires et de solidarités concrètes. Ici aussi, la présence du lien qui se manifeste dans la recherche de liberté n'est pas d'essence individuelle, faite d'égoïsme ou de repli sur soi, mais repose sur «l'expérience de l'être» dont l'essence est communautaire car s'y affirme la présence de l'autre. Si l'autonomie vient de l'individu, l'errant en ne se bornant pas à son territoire et en sortant des frontières, en appelle à l'hétéronomie : «la loi vient de l'autre, ce qui redonne au corps social sa densité et sa signification concrète " (Ibid. : 65).

S'agissant de l'aventure, Michel Maffesoli avait déjà accordé une attention à ce thème dans La Conquête du présent en la liant au tragique, au sens où "la continuité de l'existence est faite de multiples écarts, de moments particuliers qui échappent par leur précarité à la logique déterminante » (1979: 110). Ici, la notion renvoie à la pluralité de la personne, à l'importance de moments vécus pour eux-mêmes, à l'accentuation du présent, aux effervescences collectives dépassant le narcissisme et le simple souci de soi. Elle est facteur de socialité en favorisant la circulation des biens, des affects, des plaisirs, des émotions sans calcul. La postmodernité s'apparente à la prémodernité : elle ne se préoccupe pas du lendemain, ce qui compte, c'est la jouissance de l'instant, en s'accommodant du monde tel qu'il est.

Ainsi s'affirme la volonté de Michel Maffesoli de scruter les formes des cultures naissantes dans la postmodernité, en dehors des savoirs constitués, au moyen d'une démarche aventureuse et vagabonde à l'image des phénomènes qu'il décrit. Sa démarche vise, de façon holistique, à montrer les caractères organiques qui la constituent en montrant comment la socialité émerge contre le formalisme et le rationalisme des pouvoirs. Une façon d'affirmer, et ceci depuis ses premiers travaux, la puissance souterraine et les facultés instituantes travaillant contre l'ordre et l'institué.

Transversalité : récurrences des thèmes et herméneutique phénoménologique

Michel Maffesoli ne cesse dans tous ses ouvrages de parfaire la connaissance de la socialité de base en s'attardant à montrer les formes de l'organicité qui la caractérisent et en se centrant pour cela sur des thèmes récurrents pour peu à peu montrer ce qui la compose car elle ne se dévoile jamais dans une pure transparence. Des notions communes traversent ses publications et structurent ses observations toujours 
renouvelées du réel. Ces notions, même semblables, sont en fait des outils méthodologiques qui «travaillent » la socialité en acte. Elles ne seront que rappelées ici, tandis que seront amplifiées davantage les notions de "style " et d'« imaginal ", développées dans La Contemplation du monde (1993), un ouvrage qui marque une «respiration ». Outre la récurrence de ces thèmes qui traversent la pensée de Michel Maffesoli, un deuxième point est également consubstantiel à tous ses travaux : c'est sa méthode d'observation du social abordée ici allusivement. Comment saisir cette socialité en acte si ce n'est par des vérités approximatives, par une approche herméneutique qui accepte d'être inutile en refusant de participer à une connaissance instrumentale et qui s'accorde avec une société chaotique dont l'appréhension suppose «un lent travail de la pensée, le recours à la flânerie, aux retours en arrière, aux redondances, aux multiples digressions. Il faut savoir accepter ces méandres, ce sont ceux de la vie grouillante et empathique qui ne laisse pas enclore dans un système de vérités préétablies» (1992, (1995) : 21). Une pensé nomade, errante à l'image des cultures naissantes qu'il révèle, en empathie avec l'objet, car comme aime à le rappeler en s'appuyant sur Michel Foucault: «On est plus pensé par son époque qu'on ne la pense (ibid. : 20).

Des thèmes récurrentsDes oppositions ou des glissements

48 Michel Maffesoli adopte souvent la procédure des contraires pour amplifier ses thèses. Ainsi des couples d'oppositions se multiplient dans ses travaux et s'enrichissent progressivement dans le temps, tout en se complexifiant comme il a été vu dans la dialectique entre l'institué/l'instituant, entre le pouvoir/la puissance. Ici ne sont abordés que ceux qui caractérisent la base de son travail : la modernité/postmodernité, la société/socialité, le social/la socialité.

Ainsi, les cultures naissantes lisibles dans la socialité qui contribuent à la complexité du social, caractérisent le contexte postmoderne dont les valeurs naissent de la saturation des valeurs de la modernité. La modernité renvoie au mécanique, au rationnel, au linéaire, au tranché tandis que la postmodernité comporte du baroque, de l'organique, de l'ambiguïté (1996 : 47). Ces deux notions s'opposent car les cultures qui les fondent reposent sur une base différente. C'est ainsi qu'au social rationalisé, à la rationalité orientée et instrumentale, à la vision aliénée, à la distinction de la modernité, s'opposent la socialité empathique, la culture du présent non finalisée, la centralité souterraine, le vitalisme, l'agrégation sociale de la postmodernité. Michel Maffesoli entend la postmodernité comme "une catégorie spirituelle permettant de rendre compte de la saturation d'une épistèmê permettant de comprendre le moment précaire qui se situe entre la fin d'un monde et la naissance d'un autre $(1990,(1993): 22)$ et il la définit comme un «mélange organique d'éléments archaïques et d'autres on ne peut plus contemporains" (ibid.: 14). Elle ne lui apparaît pas uniquement comme une nouvelle phase dans le processus dialectique de l'Histoire, ou comme un moment dans la grande marche royale du progrès, mais plutôt «comme une sensibilité spécifique qui, toujours et à nouveau, renaîtrait en des lieux et des époques différents » (ibid. : 50). Cette opposition permet à Michel Maffesoli de cerner le nouvel esprit du temps, saisi dans des termes que ne peuvent plus éclairer ceux qui ont servi de base à l'analyse de la modernité. Ainsi, à la manière de l'idéal type wébérien, Michel Maffesoli montre deux partitions théoriques dans la sociologie : la raison et l'imagination dans le but d'arrêter les conflits en comprenant mieux les résultats de l'une et l'autre approche. 
50 Cette opposition, il la repère dans deux manières d'appréhender le monde social en empruntant à Patrick Tacussel: une approche métanoïaque (ouverte à la nature du sentiment, organique, imaginative) et une démarche paranoïaque (fondée sur la raison, la critique). La perspective métanoïaque a bien sûr la préférence de Michel Maffesoli. La liaison se fait alors avec les contextes: penser la culture postmoderne exige une attitude métanoïaque, car le sociologue est attentif à l'instituant, au souterrain, à l'intelligence du présent, à la passion et peut réaliser une "sociologie du dedans", accentuant la socialité, l'imaginaire et le quotidien dans une quête inachevée, relativiste, faite d'une humilité scientifique, rompant avec le terrorisme de la cohérence de la sociologie universelle.

51 Cela entraîne, par enchaînement, une autre opposition qui jalonne ses analyses, une opposition articulée sur la divergence entre la raison et la passion et qui consiste à discriminer la société et la socialité. L'excès d'attention portée à la société et aux éléments rationnels, intentionnels ou économiques qui la composent, refoule la socialité qui est une "empathie communalisée (1985a: 186). De même, le social se distingue de la socialité. Le social est composé d'individus liés par une fonction contractuelle, caractéristique de la modernité, la socialité compose avec des personnes (rôle) et des communautés affectuelles.

52 L'épistémologie de Michel Maffesoli se justifie encore dans un autre opposition, celle qu'il repère dans le glissement de l'identité à l'identification (1990) pour expliquer que les ensembles sociaux ne se comprennent pas à partir du pivot de l'identité qui n'est pas une valeur universelle et intemporelle comme en témoigne l'essoufflement des mouvements sociaux qui reposaient sur une revendication identitaire (mouvement ouvrier, régionaliste, étudiant, féministe, homosexuel) et qui perdent de leur intensité militante dans une institutionnalisation ou dans un dissolution. Mais ces idées se sont répandues dans le corps social et "à l'identité repérable dans la séparation sociale du sexe succède l'amour du même dans l'autre, c'est-à-dire une homosexualité affichée » (1990, (1993) : 260).

53 Au-delà de ces quelques différenciations, oppositions ou glissements de termes permettant de théoriser la socialité, Michel Maffesoli prend le temps dans son ouvrage La Contemplation du monde (1993) de développer deux notions, le style et l'imaginal, notions qui elles aussi sont transversales à sa pensée.

Le style et l'imaginal

54 Toujours à l'affût de la culture alternative née de la saturation de la modernité qu'il recherche avec un esprit qui se veut libre de tous préjugés, Michel Maffesoli veut dans La Contemplation du monde donner de l'ampleur à la culture du sentiment développée dans ses travaux antérieurs et désire "voir à l'œuvre un ensemble d'images qui, par additionnements successifs, en arrivent à constituer une conscience collective servant de soubassement tout à la fois à la vie sociale, et aux autres "tribus" qui en sont parties prenantes " (1993, (1996) : 14). Ici, cet idéal communautaire est saisi dans deux directions, le style et l'image, convergeant vers un monde imaginal défini comme « un ensemble complexe où les diverses manifestations de l'image, de l'imaginaire, du symbolique, le sens des apparences occupent, dans tous les domaines, une place primordiale » (ibid.: 15).

55 S'agissant du style, c'est celui de notre époque qui est l'objet de l'attention de Michel Maffesoli, celui qui succède au monde de l'individualisme, de la raison instrumentale, de la toute puissance techno-économique, celui dans lequel le retour des images, de 
l'émotion, la recherche d'appartenance (religieuse, ethnique ou de territoire) est prévalente. Toutes ces directions marquent une transmutation de valeurs et servent de «matrice à la socialité " (ibid.: 20) et comme il aime à le répéter, "l'anomique d'aujourd'hui est le canonique de demain » (ibid. : 20). La notion de style se substitue à la notion d'esprit du temps présente dans ses publications antérieures, tout en paraissant bien décrire un esprit du temps, du moins le climat qui le caractérise. En tout cas, Michel Maffesoli semble attribuer à la notion de style un sens proche de celui donné par Henri Lefebvre $(1958,1968)$, lié à une globalité, à une totalité inscrite à la vie quotidienne. C'est là un sens bien différent de celui de Pierre Bourdieu qui distingue les styles de vie selon les appartenances de classes (Le Pogam Y., 1985). Liée à la vie quotidienne, Michel Maffesoli définit le style comme «le cadre général dans lequel s'exprime la vie sociale à un moment donné » (1993, (1996) : 15). Le style économique caractérise la modernité comme le style esthétique permet de mieux appréhender la postmodernité. Le style donne naissance à des images qui en s'agrégeant créent une conscience collective. Le style devient une "forme formante ", Forme au sens où il est une unité dynamique permettant de saisir les contours d'une culture, formante parce que le changement de style provoque des changements de sensibilités.

Ici encore, Michel Maffesoli se dégage d'une vue marxisante tentée par une explication liant le style à une superstructure déterminée par l'infrastructure, alors qu'il renvoie en fait à une conception générale de la vie « qui conditionne l'ensemble des institutions religieuses, politiques, économiques d'une période donnée » (ibid. : 29).

Or, si une transmutation de style s'est effectuée pour Michel Maffesoli, c'est bien celle qui converge vers une manière d'être esthétique (manière d'être et de sentir en commun comme il a été vu). Le style esthétique est une vecteur de socialité comme le montrent les rassemblements sportifs, religieux ou musicaux et un vecteur de correspondance avec l'environnement naturel, liant l'écologie à cette religiosité ambiante, une manière d'être proche $\mathrm{du}$ romantisme. La présence d'une « homosocialité » se manifeste dans le lien social élaboré par la fusion et non par la distinction qu'illustrent les cultes du corps (culturisme, diététique, presse, mode, activités sportives) où le corps est construit, soigné et embelli sous le regard de l'autre afin qu'il soit vu par l'autre. C'est le plaisir d'être avec l'autre, le désir de l'autre qui prévaut et qui crée un climat qui n'est nullement un supplément d'âme comme le considère l'establishment.

La fonction agrégative du style esthétique s'exerce aussi dans le quotidien où les liens émotionnels ne se fondent pas sur une quelconque transgression, mais plutôt sur une sorte d'innocence pouvant être perverse où " tout est bon » (camaraderie amoureuse, triolisme, bisexualité, « sex groupes »). Le style de l'époque décrypté, Michel Maffesoli développe une autre dimension transversale à ses publications : le rôle de l'image.

Déjà dans La Conquête du présent Michel Maffesoli nous alertait sur l'importance de l'image sociale dans toutes les situations, image définie comme « acte constitutif radical et simultané du réel et de l'imaginaire " (1979: 15). Il parlait aussi d'une fonction imaginale où s'exprime "l'imbrication organique $d u$ banal, du fantastique, du quotidien, du fonctionnel » (ibid.: 88). La notion de monde imaginal paraît dans $A u$ creux des apparences comme réenchantement du monde. Michel Maffesoli part des travaux de Gilbert Durand qui assurent une légitimité des images et met en place les fondements d'une sociologie figurative ainsi que la réalise Patrick Tacussel (Tacussel P., 1995). La vie quotidienne s'organise autour d'images à partager et le monde imaginal 
serait en quelque sorte « la condition de possibilité des images mondaines» (Maffesoli M., 1990, (1993) : 117). Ces idées sont développées dans La Contemplation du monde où, malgré les préjugés négatifs l'égard de l'image, Michel Maffesoli légitime sa valeur heuristique car elle très proche du réel et ouvre à une sensibilité phénoménologique.

Les images partagées (en sport par exemple), renforcent le lien social et permettent une "reliance », une notion empruntée à Marcel Bolle de Bal pour signifier le ciment mystérieux, non logique, non rationnel qui s'inscrit tant dans le quotidien que dans les événements festifs liturgiques et dans les rituels. Tout comme le style, l'image est une forme formante. Elle relie, donne des attaches, car grâce à elle l'environnement n'est plus neutre, il s'anime (cf. la charge symbolique de "pays» ou de «territoire »). Et Michel Maffesoli est bien audacieux de rompre les idées convenues sur la télévision car pour lui, l'image télévisée assure une " coprésence » et favorise le réenchantement du monde en permettant d'affirmer sa souveraineté, son existence, par l'agrégation qu'autorise son aspect communiel.

61 Enfin, pour Michel Maffesoli, la socialité peut être transfigurée, autre terme transversal qui lui est cher. L'exemple du corps permet de comprendre ce passage d'une figure à une autre. Les corps "s'angélisent" (ibid.: 119) en se spiritualisant par l'attention accordée à l'apparence, à la recherche d'un jeunisme permanent ou par le développement des techniques corporelles. Ce n'est plus la logique économique qui domine. La transmutation s'opère par une ouverture à la libération, libération qui reste encore dans la logique instrumentale mais qui aboutit à la liberté, ouverte elle au présent, à l'événement, au vécu, se différenciant en cela de la libération attachée à la logique du devoir être ou à une morale du péché. Cette transfiguration s'opère aussi dans l'entreprise à la recherche de valeurs qualitatives, présentéistes, en rupture avec l'image du corps, produit industrialisé. En maximisant l'imaginal, Michel Maffesoli se situe dans le cadre d'un sociologie figurative, ou " esthético-compréhensive » (Tacussel P., 1995 : 11), car la figure permet de faire sens, de donner du sens, non pas dans une finalité visée, mais dans une communication partagée avec l'autre (1993, (1996) : 126).

Ce retour et la profusion des images, en mettant l'accent sur le style, conduit encore Michel Maffesoli à prouver le retour du sens communautaire en donnant toute son importance au lien social tissé à partir de ce qui a priori est considéré comme frivole, c'est-à-dire dans des pratiques où l'affect domine: les pratiques corporelles, la publicité, les soins du corps. Une transmutation s'opère du modèle démocratique (lointain) au modèle communautaire (image, style, forme), contribuant à rendre la socialité inquiétante.

Michel Maffesoli présente le dévoilement progressif de la socialité comme un défi intellectuel qui ne peut être relevé que par une approche spécifique. Cette démarche traverse aussi ses différents ouvrages, mais il consacre deux pauses à une réflexion épistémologique : La Connaissance ordinaire (1985) et Éloge de la raison sensible (1996) dans lesquels il développe, en se défendant des accusations dont sa sociologie est l'objet, les principes épistémologiques qui entrent en harmonie avec son objet: la socialité émergente.

Une herméneutique compréhensive et phénoménologique

Des approches synthétiques pour saisir la sociologie compréhensive de Michel Maffesoli ont déjà été tentées (Choi W., 1997). Ici, le propos vise à souligner quelques dominantes ce cette approche en montrant sa singularité dans un champ herméneutique qui n'est pas homogène (Le Pogam Y., 1995). 

sociologie, l'épistémologie de Michel Maffesoli est guidée par un schème herméneutique (Berthelot J.-M., 1990; Le Pogam Y., 1995) dont la nature est empathique, compréhensive et phénoménologique. Une telle approche part du présupposé que «le contenu latent est déjà là, sous le rêve manifeste, dans les associations que celui-ci suggère et les symboles dont il use » (Berthelot J.-M., 1990 : 74). Dans ce sens, la démarche herméneutique échappe au formalisme de procédures comme en témoignent les multiples approches de Michel Maffesoli pour saisir la socialité (re)naissante, démarche faite d'une certaine liberté, s'appuyant sur esprit libertaire clairement revendiqué. Cette approche, comme Michel Maffesoli l'admet, est faite d'insolence, de naïveté ou de trivialité même, des traits nécessaires pour penser hors des conformismes et surtout pour être en empathie avec une socialité éclatée dont il s'efforce, par le rassemblement patient d'hétérogénéités, de lui conférer une unicité en cernant ses contours, ses mouvements.

Michel Maffesoli a bien conscience que la désinvolture apparente de sa posture peut être déconsidérée, puisqu'il s'agit de développer une sociologie "spéculative", une « empirisme spéculatif» (1992, (1995) : 20) ayant pour ambition d'élaborer une raison sensible. Sa sociologie se positionne contre les attentes de la sociologie institutionnelle et se veut irrespectueuse des limites, une sociologie pratiquée aussi par Georges Balandier ou Alain Touraine. Cette démarche dionysienne et impliquée fait appel à la sociologie, à la philosophie, à l'histoire des religions, au roman ou aux recherches sur le pratiques de la vie quotidienne. En phase avec l'esprit du temps, elle n'en pas moins exigeante pour décrypter le sens des multiples formes des cultures émergentes qu'elle révèle.

Sa sociologie s'érige contre un certaine tradition héritée des pères fondateurs qui mettent le soupçon sur les pratiques et les discours. L'approche maffesoliennne valorise au contraire le sens commun et le vécu déconsidérés dans les sciences sociales qui ne peuvent admettre qu'existe une validité en soi. Or, pour Michel Maffesoli, ce sens commun est « un enracinement dynamique » et il est « l'expression du présentéisme servant de pivot entre le passé et le futur » (1996:220). Il ne se situe pas sur le versant de la critique (le régime diurne de Gilbert Durand) mais participe du «régime nocturne", non tranchant. Le sens commun est constitué par un inconscient collectif qui sourd du corps social et qui se manifeste dans les rituels, dans la socialité.

Quant au vécu, il permet de prendre en compte la passion, la mystique de l'êtreensemble, mystique au sens où le lien se réalise de manière mystérieuse. Le lien social doit être repensé en dehors des cadres de la modernité et le vécu ne doit rien à l'histoire et à la critique. Ainsi le temps vécu, par la durée bergsonienne, permet l'expression harmonique de toutes les potentialités corporelles et affectives, tandis que la critique analytique (Progrès, Révolution) fonctionne sur le temps futur qui s'effondre (1984: 125). De plus, l'attention prêtée à l'aliénation par l'intellectuel critique l'empêche de voir l'homme sans qualité dans la vie courante, trop attentif à montrer que les pratiques et les discours sont les symptômes d'autres choses (ibid. : 155). C'est ainsi que l'approche de Michel Maffesoli est compréhensive. Elle ne vise pas à trouver des explications causales. Cela explique les distances qu'il prend par rapport aux analyses critiques de Guy Debord qui pense le spectacle comme masque et aliénation (1993, (1996) : 155), alors que l'important pour lui est de faire éclater le désordre dans sa pluralité. De même prend-il des distances par rapport à l'analyse de la passion

Corps et culture, Numéro 3 | 1998 
réalisée par l'Ecole de Francfort quand il théorise sur l'orgiasme, au sens où l'analyse de la passion menée par Adorno ou Horkheimer consiste à montrer les dangers de la massification, de la violence manifeste et de la montée des irrationalismes, des signes de la décadence du capitalisme, alors que pour Michel Maffesoli, il est possible d'approcher la passion par la notion de "résidus », empruntée à Vilfredo Pareto. Cette notion qui désigne ce qui reste au-delà du processus de rationalisation, de théorisation, de justification permet à Michel Maffesoli de mettre l'accent «sur la circulation de l'effet là où l'idéologie capitaliste souligne le primat de l'ordre matériel et économique » (1982, (1991) : 25). L'influence de Pareto peut être repérée aussi par l'importance donnée par Michel Maffesoli à «la culture des sentiments", car pour Pareto, selon Julien Freund, « Les phénomènes sociaux sont principalement déterminés par les sentiments et les intérêts, et seulement d'une manière très secondaire par les raisonnements logiques et expérimentaux » (Freund J., 1974 : 292).

On comprend aussi pourquoi, fort du principe de valoriser le sens commun et le vécu, Michel Maffesoli est sensible à Alfred Schütz (1987), ou à Peter Berger et Thomas Luckmann, en rédigeant la préface de La Construction sociale de la réalité (Berger P., Luckmann T., 1986), des auteurs ouverts à une sociologie compréhensive. Ils reconnaissent, contre la sociologie traditionnelle, l'importance de la connaissance spontanée (l'homme de la rue), donnent du crédit à l'interactionnisme symbolique (comme correspondance à l'environnement, thème développé dans une sensibilité écologique qui anime Michel Maffesoli quand il développe l'idée d'une naturalisation de la culture), et établissent une distance par rapport aux théories qui épuisent le réel et par rapport à une science normative. C'est une sociologie qui substitue à l'individu économico-politique, la personne qui dans les rôles va former le théâtre social. La construction de la connaissance se réalise par chacun et non par des théories, conciliant Durkheim dans son objectivité et Weber dans sa subjectivité. C'est une sociologie qui ne craint pas non plus les contacts avec la philosophie. Bref, une sociologie compréhensive qui s'attache à saisir le sens d'une activité, d'une relation, sens qui est «subjectivement visé par les agents au cours d'une activité concrète " (Freund J., 1983, (1966) : 82).

Tout cela permet de comprendre la méfiance de Michel Maffesoli à l'égard du positivisme et du rationalisme. Du positivisme, car la vie ne peut pas être entièrement formalisée. Une labilité, une passion et du non logique existent en elle, que ne peuvent expliquer le freudisme ou le marxisme dépendants dans leur construction des sciences du moment. Michel Maffesoli, dans une filiation à Georges Gurvitch et à Georges Balandier, plaide pour le polythéisme des valeurs, pour un éloge du pluralisme, car « La société est plusieurs » (Maffesoli M., 1985b), faite d'hétérogénéités, de dynamiques différentielles et de discontinuités sociales: elle n'est pas un objet pur. D'où la proximité de Michel Maffesoli d'auteurs dont la pensée est ouverte, comme Edgar Morin, Gilbert Durand, Jean Duvignaud. Méfiance aussi à l'égard du rationalisme que discute Michel Maffesoli, moins pour le critiquer et le dépasser que pour montrer qu'il est sclérosé comme instrument de choix de l'analyse de la vie individuelle et sociale. La vie sociale est faite de situations anomiques qui résistent au carcan de l'organisation pensée a priori. La raison est un mythe fondateur de la bourgeoisie qu'il faut dépasser pour penser de manière audacieuse et comprendre les processus d'interaction, les métissages à l'oeuvre dans les sociétés complexes. Michel Maffesoli développe une approche qui ne se met pas au service d'une cause, car la globalité n'est plus alors pensée comme telle mais devient une abstraction à parfaire en fonction de buts à 
atteindre. Il s'agit donc, dans le dépassement du positivisme et du rationalisme de comprendre les actions humaines, les prendre ensemble, voir comment elles se tiennent, ce qui nécessite une approche phénoménologique qui serre les faits observés.

Cela ne signifie pas que Michel Maffesoli se distancie de toute rationalité, il s'accorde au contraire avec une rationalité ouverte, comprise comme une attitude intellectuelle faite de modestie qui relie la raison au sensible et où l'affect et l'émotionnel sont les leviers pour comprendre les phénomènes sociaux. Il faut rentrer dans la raison interne des choses en accédant au non logique ou au non rationnel, une attitude pour saisir l'existence dans son développement, procédant en cela d'une « raison vitale » ou de ce qu'il appelle «le ratio-vitalisme » au sens où il ne faut rien négliger dans ce qui nous entoure. Comment rendre compte de ce vitalisme, de la dynamique de la vie quotidienne, de actes minuscules qui la jalonnent, de la raison interne, de cette musique subtile qui émerge si ce n'est en adoptant un «esprit contemplatif » (1996: 149), une méthode amoureuse de la vie, érotique, orientée plus sur la présentation que sur la représentation, une pensée nomade, errante, bref contempler le monde et non le pénétrer?

72 Cette contemplation s'opère par la description, mode privilégié de l'approche phénoménologique. Elle permet d'appréhender les turbulences du monde en mutation dont il faut capter les formes, en se contentant de dire le réel, et en opérant plus cette séparation entre l'observateur et l'observé, ceci afin « d'épiphaniser » le réel. C'est une approche que Michel Maffesoli applique aux groupes, au jeu des apparences, aux pratiques corporelles, à l'esthétique, à la duplicité, autant de « formes » qui l'entraînent sur le chemin d'une sociologie " formiste».

73 Le formisme traverse aussi son travail pour lui permettre d'appréhender les cultures naissantes dont il veut cerner les contours ou les tendances générales par la notion de «forme ». Ces formes expriment la puissance du social (le vouloir vivre, le présent, le désir du collectif), un moyen méthodologique pour lui de faire ressortir la vie sociale en lui étant fidèle. La forme est ainsi élaborée à partir de descriptions. Le « formisme » est le cadre d'analyse dont l'ambition est de mettre en valeur ce qui est, sans imposer un devoir être. Elle préfigure aux existences individuelles et leur sert de conditions de possibilité.

Le fait de consacrer au formisme un chapitre dans ses ouvrages La Connaissance ordinaire et Eloge de la raison sensible, témoigne de l'importance qu'il accorde à ce point d'épistémologie. La forme permet à Michel Maffesoli, sur le mode empirique, de faire ressortir le changement qualitatif qui s'opère dans la postmodernité. Elle permet aussi de conjoindre des éléments séparés en créant une unicité (une cohésion d'éléments fragmentés, réunis malgré les contraires). A la manière de l'idéal type wébérien, la forme " accentue, caricature, charge le trait et par là même fait ressortir l'invisible, le souterrain, on pourrait dire le subliminal, que la science a beaucoup de mal à repérer, voire à intégrer dans ses analyses » (1996: 116).

Son travail relève bien d'une herméneutique. Il s'efforce de trouver le sens des formes qui comportent des aspects symboliques en renvoyant à un contenu plus vaste que ne le donne le sens immédiat, par exemple dans la «reliance » où il faut chercher ce qui s'enracine dans l'individu et la collectivité pour comprendre les agrégations sociales. La mémoire collective, les habitus comme incorporations de souvenirs ou de connaissances sont là pour le comprendre. Alors, la forme, comme mode épistémologique pour saisir la culture, intègre la nature archétypale des contenus 
collectifs (résidus archaïques, images) qui continuent à travailler dans les contextes nouveaux et qui façonnent les existences. L'usage des formes, comme le montre Michel Maffesoli depuis le début de ses travaux, peut être l'élément révélateur de la socialité en acte. Concrètement, elles s'objectivent dans la vie quotidienne, dans le merveilleux, dans le qualitatif comme le montrait Henri Lefebvre.

Enfin, il faudrait situer l'épistémologie de Michel Maffesoli par rapport à l'essayisme dont il se réclame et aux polémiques qu'une telle position provoque dans le champ de la connaissance. L'essai n'a pas bonne presse dans un certain champ universitaire. Ainsi Daniel Bertaux reconnaît bien qu'existent dans la sociologie maffesolienne (et dans celle de Michel de Certeau), des intuitions intéressantes, ce qui est l'avantage de l'essayisme, mais que cela provoque un envers, car l'essayiste projette sur l'univers son propre point de vue, sans aucun souci de réalisme sociologique. L'auteur argumente sur le fait que Michel Maffesoli, dans La Conquête du présent décrit le scepticisme populaire à l'égard des idéologies politiques mais s'éloigne du réel quand il réduit ces grandes idéologies à une seule, l'idéologie mortifère du progrès, alors que pour Daniel Bertaux on peut vouloir prendre en main sa destinée et il ne s'agit pas de résignation désabusée (Bertaux D., 1983). Mais Michel Maffesoli à plusieurs reprises répond à ces accusations d'essayisme. Cette démarche lui permet d'être proche de son objet, la vie sociale, un objet jamais explicable dans sa totalité, et de ne pas mépriser le plus grand nombre en ne réservant pas la sociologie à une élite. Et puis, il faudrait discuter plus longuement l'argument du "réalisme sociologique ", car la sociologie maffesolienne s'appuie aussi sur bon nombres de recherches même s'il est vrai que ses références sont multiples, tourbillonnantes et qu'elles traversent l'orthodoxie du champ. Une vraie liberté qui brise quelque part les règles du métier mais dont les intuitions séduisent et sont stimulantes pour la compréhension de la dynamique sociale.

Cette présentation a voulu rester fidèle aux vues de Michel Maffesoli qu'il fallait restituer dans le champ de la sociologie contemporaine en montrant la multiplicité des pratiques interrogées et les principes épistémologiques qui guident ses travaux. Par la socialité qu'il révèle au moyen de pistes toujours renouvelées, il éclaire peu à peu cette nébuleuse qu'est le pouvoir d'agrégation des individus ou des groupes dans la société en montrant les forces obscures qui font que les liens se font. Sans doute de nouvelles ouvertures pourraient être encore exploitées qui participent de son approche sensible aux affects? Ce sont par exemple les formes de désamour, de défections du lien, faites de passions qui se refroidissent et désagrègent le lien. Les formes de désamour montrent aussi que le social est parcouru par des tensions dans les sensibilités collectives qui parcourent les pratiques sociales et participent aussi à la dynamique dans la vie quotidienne.

78 Enfin de manière plus circonscrite à notre champ préoccupé de pratiques corporelles et sportives, il faudrait voir comment les problématiques développées par Michel Maffesoli ont de quoi séduire des chercheurs au moins dans deux directions. Par son approche compréhensive et phénoménologique d'abord, car elle contient des espaces de liberté permettant de voir que le corps et le sport peuvent être interrogés par une autre entrée que l'analyse critique ou structurale, par le propos subversif qu'elle contient ensuite, en montrant comme l'instituant travaille contre l'institué en éducation physique par exemple, une discipline d'enseignement où le corps est central et qui dépend de l'institution scolaire imposant des normes. Et puis de manière plus générale, il est salutaire de voir comment une telle sociologie bouscule les normes 
admises et introduit du bruit dans l'orthodoxie en regardant dans une autre direction les phénomènes sociaux sans prétendre dégager une quelconque vérité, mais en les approchant par touches successives et en rendant ainsi un peu moins opaque la nébuleuse sociale.

\section{BIBLIOGRAPHIE}

Ansart P. (1990) Les Sociologies contemporaines. Paris, Ed. du Seuil.

Berger P., Luckmann T. (1986) La Constuction sociale de la réalité. Paris, Méridiens/Klincksieck.

Bertaux D. (1983) Vie quotidienne ou mode de vie, in : Revue suisse de sociologie, 1, 67-84.

Berthelot M. (1990) L'Intelligence du social. Le pluralisme explicatif en sociologie. Paris, PUF.

Bolle de Bal M. (1989) Voyages au ceux des apparences. La quête d'une éthique de l'esthétique ?

in : Revue de l'Institut de Sociologie, 1/2, 193-199.

Choi W. (1997) La méthode compréhensive de M. Maffesoli, in : Maffesoli M. (dir.), Sociétés, La

pulsion d'errance, 56, 29-43.

Durand G. (1975) Sciences humaines et tradition. Berg International Editeurs.

Durand G. (1979) Préface, La Conquête du présent. Pour une sociologie de la vie quotidienne. (Maffesoli M.), Paris, PUF.

Durand G. (1985) Une réponse à la sociologie française, in : (sous la direction de Maffesoli M.) Une anthropologie des turbulences, Berg International Editeurs.

Freund J. (1966) Sociologie de Max Weber. Paris, PUF (3è édition 1983).

Freund J. (1974) Méthodologie et épistémologie comparées d'Emile Durkheim, Vilfredo Pareto et Max Weber, in : Recherches Sociologiques, Vol V, 2, 282-309.

Goffman E. (1974) Les Rites d'interaction. Paris, Ed. de Minuit.

Lefebvre H. (1958) Critique de la vie quotidienne, Tome I, Introduction. Paris, Ed. de l'Arche (1ère édition Grasset 1946).

Lefebvre H. (1968) La Vie quotidienne dans le monde moderne. Paris, Gallimard.

Le Pogam Y. (1985) Raison symbolique et raison utilitaire du goût sportif. A.P.S. et vie quotidienne, in : Recherches en Activités Physiques et Sportives, Marseille, 1, 97-108.

Le Pogam Y. (1995) L'anthropo-sociologie poétique de Pierre Sansot : les sports et de sensible, in : Le Pogam Y. (dir.), Corps et Culture, Le développement du sport. Enjeux institutionnels et enjeux de connaissance, 1, Montpellier, 102-138.

Maffesoli M. (1976) Logique de la domination, Paris, PUF.

Maffesoli M., Pessin A. (1978). La violence fondatrice. Paris, Ed. Champ Urbain.

Maffesoli M. (1979) La Violence totalitaire, Paris. PUF. Réed. (1994) La Violence totalitaire. Essai d'anthropologie politique. Paris, Méridiens/Klincksieck. 
Maffesoli M. (1979) La Conquête du présent. Pour une sociologie de la vie quotidienne. Paris, PUF.

Maffesoli M. (1981) La Dynamique sociale. La société conflictuelle. Thèse d'Etat, Lille, Service des publications des thèses.

Maffesoli M. (1982) L'Ombre de Dionysos. Contribution à une sociologie de l'orgie. Paris, Librairie Méridiens/Anthropos. Rééd. (1991) Le Livre de Poche, Biblio-Essais, 4131.

Maffesoli M. (1984) Essai sur la violence banale et fondatrice. Paris, Librairie Méridiens/Klincksieck.

Maffesoli M. (1985a) La Connaissance ordinaire. Précis de sociologie compréhensive. Paris, Librairie des Méridiens.

Maffesoli M. (1985b) La société est plusieurs, in : Maffesoli M. (sous la direction de) Une anthropologie des turbulences. Berg International Editeurs, 175-180.

Maffesoli M. (1988) Le Temps des tribus. Le déclin de l'individualisme dans les sociétés de masse. Paris, Méridiens-Klincksieck. Rééd. (1991) Le Livre de Poche, Biblio-Essais, 4142.

Maffesoli M. (1990) Au creux des apparences. Pour une éthique de l'esthétique. Paris, Plon. Réed. (1993) Le Livre de Poche, Biblio-Essais, 4184.

Maffesoli M. (1992) La Transfiguration du Politique. La Tribalisation du Monde. Paris, Grasset/ Frasquelle. Réed (1995) Le Livre de Poche, Biblio-Essais,

Maffesoli M. (1993) La Contemplation du Monde. Figure du style communautaire. Paris, Grasset/ Frasquelle. Réed (1996) Le Livre de Poche, Biblio-Essais, 4223.

Maffesoli M. (1996) Eloge de la raison sensible. Paris, Grasset.

Maffesoli M. (1997) Du nomadisme. Vagabondages initiatiques. Paris, Le Livre de Poche, Biblio-Essais, 4255 .

Schütz A. (1987) Le Chercheur et le quotidien. Paris Méridiens/Klincksieck.

Tacussel P. (1995) Mythologie des formes sensibles. Balzac et les Saint-Simoniens ou le destin de la modernité. Paris, Méridiens Klincksieck.

\section{RÉSUMÉS}

Les recherches de Michel Maffesoli visent à comprendre la dimension plurielle du social en privilégiant des thèmes comme l'imaginaire, l'émotion, les affects, le sensible. En scrutant les pratiques banales de la vie quotidienne au moyen d'une approche compréhensive, il établit une harmonie entre l'objet de sa recherche, la socialité, et une méthode dégagée des pensées convenues. Il révèle ainsi les cultures naissantes dans la postmodernité.

The researches of Michel Maffesoli aim to understand the social plural dimension, encouraging themes like imaginary, emotion, affects, sensitive. Scanning ordinary practices of every day life, he institutes an harmony between the object of his research, the sociality, free of conventional thoughts. He shows then the nascent cultures in postmodernity.

\section{INDEX}

Mots-clés : imaginaire, postmodernité, socialité, vie quotidienne

Keywords : every day life, imaginary, postmodernity, sociality 


\section{AUTEUR}

\section{YVES LE POGAM}

Faculté des Sciences du Sport et de l'Éducation Physique-Université Montpellier I.

Équipe «Corps et Culture » 